\title{
Cannabis Use and Disorder Transitions Among a Mixed Community Sample of At-Risk Adolescents and Adults: A Prospective New Zealand Study
}

\author{
Jan Bashford ${ }^{*}$, , Jan Copeland ${ }^{2}$ and Ross Flett ${ }^{3}$ \\ ${ }^{I}$ School of Psychology, Massey University, Palmerston North, New Zealand \\ ${ }^{2}$ National Cannabis Prevention and Information Centre, University of New South Wales, Sydney, Australia \\ ${ }^{3}$ School of Psychology, Massey University, Palmerston North, New Zealand
}

\begin{abstract}
Introduction and Aims: The trajectories of cannabis use disorder (CUD) require more comprehensive delineation to expedite recognition of incubating dependence among high-risk users. This study examined baseline cannabis use and CUD over 12 months using DSM-IV/ICD10 diagnoses to distinguish transition groups.

Design and Methods: In a prospective naturalistic design, 194 heterogeneous cannabis users (128 adolescents, 66 adults) aged 13-61 years were voluntarily recruited and assessed at baseline, and then re-assessed 12-months later.

Results: Most participants met criteria for a baseline CUD (70\% dependence, 20\% abuse), 12 adolescents were 'diagnostic orphans', and 5 symptom-free. At follow-up, 25\% adolescents reported using less, $6 \%$ the same level, and $69 \%$ using more cannabis. Significantly increased symptoms and dependence severity were reported, with no adolescent/adult differences evident. Three diagnostic transition groups were identified. While $84 \%$ adolescents $(n=108)$ remained stable, $5 \%(n=7)$ had improved, $10 \%(\mathrm{n}=13)$ had deteriorated. 'Deteriorators' scored significantly higher than 'improvers' on cannabis use, symptoms, and dependence severity measures. A subjective loss of control over cannabis use was among the earliest DSM-IV features among younger users on a trajectory towards dependence. Most participants (79\%) anticipated difficulty trying to reduce/quit their use

Discussion and Conclusions: Younger adolescents can rapidly develop cannabis dependence, reporting similar and equally severe symptoms as longer-term adult users.

Impaired control over use occurs early in trajectories towards dependence. The seeming intractability of problematic cannabis use calls for concerted cannabis screening and early intervention (SEI) efforts at an earlier age to avert or reduce harmful consequences of cannabis use in the community.
\end{abstract}

Keywords: Cannabis, cannabis dependence, cannabis use trajectories, marijuana, public health SEI, screening.

\section{INTRODUCTION}

Cannabis is by far the most widely used illegal drug worldwide, estimated at approximately $4.5 \%$ of the global population aged from 15 years [1] with much higher rates among adolescents [2-4]. A marked increase in cannabis treatment-seeking, particularly among younger users, calls for a concerted public health response to cannabis-related harms [2-4].

Adolescence is a biological and developmental period of addiction vulnerability [5]. Cannabis dependence develops twice as rapidly in adolescents than adults at any consumption level [6-9]; approximately $14-16 \%$ adolescentonset and $8 \%$ adult-onset users become dependent [3]. While early cannabis initiation and entrenched use confer the highest risk of dependence and other adverse outcomes

*Address correspondence to this author at the School of Psychology, Massey University, Private Bag 11 222, Palmerston North 4442, New Zealand; Tel: 646 356-9099, Ext. 2040; Fax: 646 350-5673;

E-mail: janbashford@gmail.com
[7-11], even occasional (weekly) use continued into young adulthood predicts later drug and other problems [12-14]. Recognizing early manifestations of cannabis use disorder (CUD) is crucial for identifying those for whom timely intervention might avert further harm. As yet, relatively little is known about the natural history of cannabis dependence [15].

Adolescents from the 1970's typically initiated cannabis use around 15-18 years, used 'experimentally'/intermittently, and discontinued by the mid-to-late twenties [16]. However, incidence, escalation, and persisting cannabis use and CUD was a nascent trend in more recent prospective studies of cohorts aged in their mid-late 20s [10, 14, 17-22] and 30s $[13,16]$. Cannabis use appears less transient than previously thought. Other age-related trends in recent decades are preadolescent cannabis initiation, and prolongation of initiation risk beyond adolescence [20].

Researchers have begun modeling cannabis use trajectories spanning adolescence through early-mid adulthood [10,21-23]. For example, prototypical subgroups 
include: high chronic, decreasers, increasers, experimental users, abstainers, 'fling', rare. Conjoint/comorbid cannabis, alcohol, and tobacco use trajectories are also appearing [14, 24-26].

Another natural history approach involves temporal patterning of symptoms among users on a trajectory to dependence; a 'subjective loss of control' was among the earliest, most prevalent DSM-III-R features [27-29]. Likewise, Australian users aged 20-21 years most frequently endorsed DSM-IV 'persistent desire to cut down/control use' (10\%; 91\% dependent users) and 'used more/longer than intended' ( $8 \% ; 84 \%$ dependent users) [30]. US adolescents aged 12-18 years [31] reported 'continued use despite a physical/psychological problem' (45\%; 60\% dependent users) 'tolerance' $(35 \% ; 51 \%$ dependent users $)$, and 'used more/longer than intended' (21\%;35\% dependent users). By contrast, frequent and infrequent German adolescent users aged 14+ years reported similar symptoms, with withdrawal $(17 \%)$, tolerance $(15 \%)$, and loss of control (14\%), most prevalent [32].

The variability in the symptoms pattern in these studies appears partly related to consumption level and design effects, such as age composition, period, country, recruitment origins, diagnostic assessments versus retrospective recall, and 'risk' level among samples. As yet, no prospective studies with mixed adolescent-adult community samples have been reported.

New Zealand is a world leader in per capita cannabis use [33]. Almost half (46.4\%) of New Zealanders report lifetime use, and one in seven past year use [34]. Significantly higher use (one in four) is reported among New Zealand's indigenous Maori population [35]. Given both rising consumption and ever-younger initiation worldwide $[33,36]$ cannabis use and disorder trajectories require more comprehensive delineation to expedite recognition of incubating dependence in order to intervene effectively among younger high-risk users. To supplement the sparse literature on the natural history of cannabis use and dependence development, this paper presents data collected in a baseline and 12-month follow-up interview with a mixed adolescent-adult sample of at-risk cannabis users recruited in New Zealand as part of research aimed at developing a brief screener for cannabis problems and reported elsewhere [37].

\section{AIMS}

With adolescent-adult comparisons at both temporal points, this study prospectively examined (1) cannabis use and CUD in a heterogeneous adolescent-adult community sample; (2) the natural history of cannabis use and diagnostic transitions 12 months later, and (3) the differential association of diagnostic transitions with the key variables in this study.

\section{METHODS}

\section{Participants}

Participants were 138 adolescents (aged 13-18 years) and 73 adults (19-61 years) from diverse community settings: drug treatment $(17 \% ; n=6$ adolescents, 29 adults); Police Youth Aid and alternative education programmes for at-risk adolescents $(23 \%, n=48$ adolescents); adult justice $(3 \%, n=7$ adults); Maori community health services ( $2 \%, \mathrm{n}=5$ adults); non-treatment general community $(16 \%, n=14$ adolescents, 19 adults); tertiary students and jobseekers $(15 \%, n=23$ adolescents, 8 adults); secondary school students $(24 \%, n=52$ adolescents).

Liberal inclusion criteria required participants had used cannabis at least once in the past 12 months, were at least 13 years of age, English-literate to year eight level to oversample younger users, with heterogeneity within both age groups.

Twelve months later, 95\% $(n=200)$ were located and $92 \%$ ( $\mathrm{n}=194 ; 128$ adolescents, 66 adults) re-interviewed. Participants lost to follow-up (10 adolescents, 7 adults) had either left the region/ country $(n=8)$, failed to return multiple phone calls/declined interview $(n=6)$, or were in prison/juvenile detention $(n=3)$. Although predominantly male $(70 \%)$, the roughly proportional drop-out across adolescent/adult groups indicated no selective attrition due to age or recruitment setting.

\section{Assessment}

A face-to-face interviewer-administered schedule and self-completed instruments assessed: demographics, cannabis use, other drug use, CUD, dependence severity, general and psychological health, cannabis-related problems, quit attempts, and treatment-seeking. Only key measures relevant to the present study aims are reported here.

Current (90-day) cannabis consumption was assessed using the Timeline Followback interview (TLFB) [38, 39]. The Syva EMIT urinalysis procedure verified clinical participants' $(n=40)$ self-reported consumption [40]. Other drug use was recorded using the Drug History Questionnaire (DHQ) [41]. Twelve-month CUD diagnoses from the Diagnostic and Statistical Manual of Mental Disorders, fourth revision (DSM-IV) [42], and the International Classification of Diseases tenth revision (ICD10) [43] were obtained using the Drug Use module of the Composite International Diagnostic Interview (CIDI)-Auto, version 2.1 [44]. The Severity of Dependence Scale (SDS) [45] provided another measure of 6-month CUD.

At follow-up, modified measures ascertained 12-month change in cannabis use and disorder. The CIDI-Auto, the TLFB interview, and the SDS were re-administered as at baseline.

\section{Procedure}

This study received institutional ethical approval. The absence of a sampling frame of cannabis users in the community ruled out assembly of a random representative sample from this "hidden population" [46]. Voluntary, nonreimbursed participants were recruited utilizing procedures apposite for population subgroups and recruitment settings. The recruitment strategy featured initial invitation to participate by: clinicians to eligible drug treatment clients; Youth Aid and Probation Officers to at-risk adolescents and adult offenders, respectively; campus counsellors or nurse to tertiary, work training, and secondary school students, and on-campus A4 invitation poster displays. To preserve recruitment integrity among specific subgroups, the researcher provided brief training and checklist-type 
guidelines for recruitment personnel. Additionally, a chainreferral 'snowball sampling' [46] technique, in which the researcher seeks contacts or referrals from participants to other cannabis users in their social networks, was employed among general population participants. This strategy has been used successfully to access similar "hidden populations" [46]. Clinician certification of competence, recruitment officer and parent/guardian signatures, or Principal/Board of Trustees' permission, was obtained for participants under 16 years. All participants signed informed consent.

All assessment interviews were conducted by the principal investigator (JB) at participant-elected times and venues. Baseline interviews were conducted between December 2003 and August 2005 at drug treatment clinics, various community interview rooms, student health services, participants' own homes, a community youth support facility and, occasionally, in private areas in cafes and taverns. Assured that their non-identifiable data would remain accessible to only the interviewer, respondents were thanked, reminded to expect follow-up contact in 12 months, and verified their tracking/locator details. Follow-up interviews were conducted approximately 12 months later (mean 366 days; $S D=10.09$, range: $318-407)$. Most (77\%) were face-toface, $20 \%$ by telephone, and $3 \%$ by post/email. Treatment information was provided if requested or indicated at both assessments.

\section{Data Analyses}

Data were analysed using SPSS for Windows Version 12.0 [47]. Descriptive statistics with adolescent/adult comparisons on cannabis use, symptoms, diagnoses, dependence severity, and other drug use at both temporal points are presented. We calculated participants' diagnostic change at 12-month follow-up and distinguished 3 common transition groups (stable/same diagnosis, improved/less severe diagnosis, deteriorated/more severe diagnosis). A series of t-tests were then conducted to examine the differential association between transition group membership (improved vs deteriorated) and the key variables in this study.

\section{RESULTS}

There were no significant differences between the follow-up $(n=194)$ and lost to follow-up $(n=17)$ samples in terms of age, education, severity of dependence, and psychological health (anxiety, depression). The lost to follow-up sample had reported significantly more cannabis use in the past 90 and past 30 days, and significantly more symptoms (all $\mathrm{p}<.01$ ). All descriptive and inferential statistics reported are based on the follow-up $\mathrm{N}$ of 194.

\section{Sociodemographics}

Participants were 70\% Caucasian, 25\% Maori (New Zealand's indigenous population), and 5\% Maori/Caucasian. The mean age was 20.5 years (range: $13-61) ; 56 \%(\mathrm{~N}=118)$ were male. Participants' generally low educational and socioeconomic status reflected in unemployment rates which persisted at follow-up $(12-13 \%$ were in full-time employment). Almost one-third of adolescents (30\%) reported their parent/s used cannabis regularly. More than half the sample (53 versus $45 \%$ at baseline) reported being in a relationship, with most $(66 \%$ of adolescents, $43 \%$ of adults) having partners who also used cannabis regularly.

\section{Cannabis Use}

Adolescents were significantly younger (mean 12.10 years, $S D=1.8$ ) than adults (mean 14.57 years, $S D=4.4$ ) when they first tried cannabis, $t(192)=-5.48, p<.001$, and began using regularly, $t(179)=-7.56, p<.001$ (Table 1).

At baseline adults reported using significantly more often than adolescents over the past $90, t(192)=-3.94, p<.001$, and 30 days, $t(192)=-4.20, p<.001$. At follow-up, however, while adults recorded generally-persistent consumption, adolescents reported significantly increased use in the past $90, t(127)=-4.45, p=.001$ and 30 days, $t(127)=-3.00$, $p<.01$. More specifically, while $25 \%(\mathrm{n}=32)$ adolescents were now using less often, $6 \%(n=8)$ were using at the same level, the majority $(69 \%, n=88)$ were using more often than at baseline. Further, more than half of all adolescents $(57 \%)$ reported using the more potent cannabis preparations.

Spearman correlations revealed a significant association between laboratory urinalysis data and clinical participants' $(\mathrm{n}=40)$ self-reports of consumption over the past 30 days $\left(\Upsilon_{\mathrm{s}}\right.$ $=.43, p<.01)$.

\section{Other Drug Use}

At baseline, 91\% participants reported currently using alcohol and 93\% tobacco, with no significant adult/adolescent differences. Recent/regular use of other drugs was not common except for BZP/benzylpiperazine (party pills), with $40 \%$ reporting past month, and $17 \%$ weekly, use. At follow-up, 94\% reported alcohol use, with reduced tobacco use ( 84 from $93 \%$ ) across both age groups. Two-thirds of adolescents were now drinking significantly more often than at baseline, $t(123)=-2.36, p<.05$. Threequarters $(83 \%$ adolescents, $61 \%$ adults $)$ reported significantly increased weekly BZP use $(52 \%), t(79)=-$ $5.56, p<.001$.

\section{Cannabis Use Disorder}

At baseline, $90 \%$ obtained a CUD diagnosis (70\% DSMIV dependence, $20 \%$ abuse, $66 \%$ both diagnoses) (Table 2 ). Only 17 participants (8\%) had no diagnosis. Of these, 12 adolescents were 'diagnostic orphans' (i.e., met 1-2 dependence criteria only) [48] and 5 were asymptomatic. Adolescents endorsed a mean of $6.1(S D=3.4$, range: $0-13)$ and adults $6.4(S D=2.8$, range: $0-13)$ from 13 combined DSM-IV/ICD-10 symptoms. Most frequently endorsed were: 'use in hazardous situations' (77\%), 'using more/longer than intended' ( $72 \%)$, 'time spent obtaining, using, or recovering' $(64 \%)$, and 'persistent desire to cut down/ control use' $(63 \%)$. Other than adolescents more likely to report cannabis-related work/school or interpersonal problems $(p<.01)$, and adults more likely to report withdrawal $(p<.05)$, there were no significant adolescent/adult differences.

Twelve months later, 93\% obtained a CUD diagnosis (76\% dependence, $17 \%$ abuse, $74 \%$ both diagnoses). ICD10 diagnoses were similar (both assessments). The most frequently endorsed criteria were 'use in hazardous situations' (80\%), then markedly increased 'tolerance' (79\% vs 53\%), 'using more/longer than intended' (79\%), 'persistent desire to control/cut down' (71\%). Adolescents 
Table 1. Patterns of Cannabis Use Among the Baseline and Follow-Up Samples (n=194)

\begin{tabular}{|c|c|c|c|c|c|c|}
\hline \multirow[t]{2}{*}{ Variable } & \multicolumn{2}{|c|}{$\begin{array}{c}\text { Adolescents }(<=18 \text { Yrs }) \\
(n=128)\end{array}$} & \multicolumn{2}{|c|}{$\begin{array}{l}\text { Adults }(19+\text { Yrs }) \\
\quad(n=66)\end{array}$} & \multicolumn{2}{|c|}{$\begin{array}{l}\text { Total Sample } \\
\quad(n=194)\end{array}$} \\
\hline & Baseline & Follow-Up & Baseline & Follow-Up & Baseline & Follow-Up \\
\hline \multicolumn{7}{|l|}{ Age of first use (yrs) } \\
\hline Mean & 12.10 & & 14.57 & & 12.94 & \\
\hline SD & 1.85 & & 4.41 & & 3.19 & \\
\hline Ever regular use? (weekly +) (\%) & $113(88.3)$ & & $66(100)$ & & $179(92)$ & \\
\hline \multicolumn{7}{|c|}{ Age of first regular use (weekly +$)(y r s)$} \\
\hline Mean & 13.47 & & 17.61 & & 14.98 & \\
\hline SD & 1.74 & & 5.39 & & 4.04 & \\
\hline SD & 1.46 & & 7.91 & & 6.57 & \\
\hline Range & $0-12$ & & $0-37$ & & $0-37$ & \\
\hline \multicolumn{7}{|l|}{ Days of use past 90 days } \\
\hline Mean & 45.04 & 53.46 & 62.70 & 58.33 & 51.04 & 55.12 \\
\hline SD & 29.16 & 32.50 & 30.70 & 32.50 & 30.78 & 32.57 \\
\hline Range & $0-90$ & $0-90$ & $0-90$ & $0-90$ & $0-90$ & $0-90$ \\
\hline \multicolumn{7}{|l|}{ Days of use past 30 days } \\
\hline Mean & 14.98 & 17.65 & 21.62 & 19.43 & 17.24 & 18.26 \\
\hline
\end{tabular}

endorsed a mean of 7.66 and adults 7.22 (both ranges: 0-13) symptoms, reflecting a significant increase among both adolescents, $t(127)=-7.52, p<.001$, and adults, $t(65)=-$ 2.94, $p<.01$. Again, adolescents were more likely to report cannabis-induced work/school and interpersonal problems $(p<.001)$ and adults more likely to report use in hazardous situations (driving stoned) $(p<.001)$.

Dependence severity (SDS) scores depicted a similar pattern, with no significant adolescent/adult differences in scores or items endorsed at either assessment. Both groups scored significantly higher at follow-up (Table $\mathbf{3}$ ).

\section{Twelve-Month Diagnostic Transitions and Association with Key Variables}

As Table 2 reflects, at follow-up only minor movement between diagnostic categories was evident; 86\% (108 adolescents, 58 adults) had remained stable/same diagnosis, 9\% (13 adolescents, 4 adults) had deteriorated (now had a diagnosis/progressed from abuse to dependence), while $5 \%$ (7 adolescents, 4 adults) had 'improved' (dependence to abuse/now in remission).

The 'deteriorated' transition group included 4 (of 12) baseline diagnostic orphans: one obtaining dependence, and 3 abuse, diagnoses; one asymptomatic adolescent now with abuse, and 8 adolescents and 4 adults had progressed from abuse to dependence, diagnoses.

The 'improved' transition group comprised 3 adults and 6 adolescents with dependence reducing to abuse diagnoses, one adolescent from abuse to diagnostic orphan, and one adult from abuse to remission.

Other noteworthy baseline (no diagnosis) transitions included: 7 (of 12) diagnostic orphans remained unchanged, and one now in remission; three (of 5) baseline asymptomatic adolescents had become diagnostic orphans, with only one remaining symptom-free.

We compared, via a series of independent samples t-tests, 'deteriorated' and 'improved' groups on this study's key variables (Table 4). One set of analyses reports differences between the two groups at baseline (B). The second set of analyses considers differences between the two groups at follow- up (F-U).

As Table 4 indicates, there were no differences between the two diagnostic transition groups at baseline (B) in terms of cannabis use, with the exception of the adult subgroup where the 'improved' group reported significantly less 30day cannabis use than the 'deteriorated' group. Adolescent "improvers" reported significantly higher symptoms and SDS scores at baseline than adolescent 'deteriorators'. 
Table 2. Proportion (\%) of Adolescents and Adults Meeting 12-Month DSM-IV/ICD- 10 Diagnoses, and Each of the Criteria, for Cannabis Use Disorder on the CIDI-Auto Among Baseline and Follow-Up Samples (n=194)

\begin{tabular}{|c|c|c|c|c|c|c|}
\hline \multirow[t]{2}{*}{ Variable } & \multicolumn{2}{|c|}{$\begin{array}{l}\text { Adolescents }(<=18 \text { Yrs }) \\
(n=128)\end{array}$} & \multicolumn{2}{|c|}{$\begin{array}{l}\text { Adults (19+ Yrs) } \\
\qquad(\mathrm{n}=66)\end{array}$} & \multicolumn{2}{|c|}{$\begin{array}{l}\text { Total Sample } \\
\quad(\mathrm{n}=194)\end{array}$} \\
\hline & Baseline & Follow-Up & Baseline & Follow-Up & Baseline & Follow-Up \\
\hline \multicolumn{7}{|l|}{ 12-month DSM-IV Diagnoses } \\
\hline Cannabis Dependence & 67 & 73 & 76 & 82 & 70 & 76 \\
\hline Cannabis Abuse only & 19 & 18 & 20 & 15 & 20 & 17 \\
\hline Cannabis Dependence \& Abuse & 65 & 73 & 70 & 77 & 66 & 74 \\
\hline \multicolumn{7}{|l|}{ 12-month ICD-10 Diagnoses } \\
\hline Dependence Syndrome & 66 & 72 & 73 & 80 & 68 & 75 \\
\hline Harmful Use only & 5 & 3 & 12 & 8 & 7 & 5 \\
\hline Dependence Syndrome \& Harmful Use & 56 & 59 & 70 & 65 & 61 & 61 \\
\hline No Diagnosis & 12.5 & 9.4 & 1.5 & 3.0 & 8.8 & 7.2 \\
\hline 'Diagnostic orphans' (1 or 2 dependence criteria) & 9.4 & 7.8 & 0 & 1.5 & 6.2 & 5.7 \\
\hline No symptoms/criteria & 3.1 & 1.6 & 1.5 & 1.5 & 2.6 & 1.5 \\
\hline \multicolumn{7}{|l|}{ Dependence Criteria Met } \\
\hline Tolerance: need more to achieve desired effect (or) same amount has less effect. & 53 & 80 & 50 & 76 & 51 & 79 \\
\hline Withdrawal symptoms when cut down (or) use to avoid/relieve symptoms. & 26 & 48 & 44 & 44 & 32 & 47 \\
\hline Used more, or over longer periods, than intended. & 69 & 77 & 79 & 83 & 72 & 79 \\
\hline Strong desire to use/compulsive use. & 43 & 52 & 53 & 58 & 46 & 54 \\
\hline Persistent desire (or) unsuccessful efforts to cut down or control use. & 62 & 66 & 67 & 79 & 63 & 71 \\
\hline Great deal of time spent using, obtaining, or recovering. & 61 & 52 & 71 & 64 & 64 & 56 \\
\hline $\begin{array}{l}\text { Important social, occupational or recreational activities given up or reduced because of } \\
\text { cannabis use }\end{array}$ & 31 & 55 & 29 & 30 & 30 & 47 \\
\hline Continued use despite persistent cannabis-related medical problems & 22 & 20 & 29 & 21 & 24 & 20 \\
\hline (or) & & & & & & \\
\hline Continued use despite persistent cannabis-related psychological problems & 49 & 61 & 62 & 64 & 54 & 62 \\
\hline \multicolumn{7}{|l|}{ Abuse/Harmful Use Criteria Met } \\
\hline Interfered with role obligations at work, school, or home & 45 & 66 & 24 & 27 & 38 & 53 \\
\hline Recurrent use in physically hazardous situations & 74 & 74 & 82 & 92 & 77 & 80 \\
\hline Recurrent legal problems & 26 & 36 & 23 & 38 & 25 & 37 \\
\hline Recurrent social/interpersonal problems caused or exacerbated by cannabis use & 48 & 78 & 33 & 47 & 43 & 68 \\
\hline
\end{tabular}

At follow up (F-U) there were consistent differences between the diagnostic transition groups in terms of both cannabis use and total symptoms. Individuals whose diagnosis had deteriorated were using significantly more cannabis and had significantly higher symptom levels. These same individuals also reported higher SDS scores at follow up (although the difference was not significant for the adolescent sub-group).

\section{Quit Attempts and Treatment-Seeking}

Two-thirds (69\%) of the sample reported unsuccessfully attempting to quit/reduce their use prior to baseline and 55\% $(\mathrm{n}=107)$ reported doing so within the follow-up period, most $(\mathrm{n}=77)$ without assistance. While treatment seekers (17 adolescents, 13 adults) and non-seekers reported similar baseline use, at follow-up treatment seekers' use level was significantly higher than non-seekers in the past $90[t(105)=$
$-2.80, p<.01]$ and $30[t(105)=-2.85, p<.01]$ days, explained by the adolescents. Nevertheless, $86 \%$ (both assessments) believed they did not require any help to cut down/quit.

\section{DISCUSSION}

This naturalistic, prospective study examining cannabis use and disorders among a mixed adolescent-adult community and treatment-seeking sample reporting high levels of cannabis use at baseline found $90 \%$ met criteria for a 12-month DSM/ICD diagnosis of CUD. Twelve months later, significantly increased cannabis consumption (adolescents), symptoms, and dependence severity were reported, with no significant adolescent/adult differences evident. As in local [19] and international [16-18] prospective research, rather than a tailing-off or remission, there was clear evidence of generally-persisting use among 
Table 3. Descriptive Statistics for the Severity of Dependence Scale (SDS): Individual items and Total Score Among Adolescents and Adults at Baseline and Follow-Up

\begin{tabular}{|c|c|c|c|c|}
\hline \multirow[t]{2}{*}{ Scale Item } & \multicolumn{2}{|c|}{ Adolescents $(<=18$ Years $)(n=128)$} & \multicolumn{2}{|c|}{ Adults $(19+$ Years $)(n=66)$} \\
\hline & Baseline & Follow-up & Baseline & Follow-Up \\
\hline During the last 6 months....... & M (SD) & M (SD) & M (SD) & M (SD) \\
\hline Did the prospect of missing a smoke make you very anxious or worried? & $.66(.81)$ & $1.08(.81) * * *$ & $.88(.94)$ & $.89(.70)$ \\
\hline How much did you worry about your cannabis use? & $.88(.66)$ & $1.3(1.9) *$ & $1.03(.82)$ & $1.27(.73) *$ \\
\hline How difficult would you find it to stop or go without cannabis? & $1.00(.82)$ & $1.38(.96) * * *$ & $1.10(.88)$ & $1.44(.79) * *$ \\
\hline Total SDS Score & 4. $00(2.4)$ & $5.50(3.0) * * *$ & $4.57(3.2)$ & $5.56(2.8) * *$ \\
\hline
\end{tabular}

M: mean. SD: standard deviation. ${ }^{*} \mathrm{p}<.05,{ }^{* *} \mathrm{p}<.01,{ }^{* * *} \mathrm{p}<.001$; all tests two-tailed.

adults and significantly increased use among adolescents. More than half had tried to reduce/quit their cannabis consumption without success. Nevertheless, despite having worried and wishing they could stop (Table 3), the majority (86\%) paradoxically believed their cannabis use was not a problem in their lives. Younger users in particular appeared to have little knowledge or insight (and frequently none whatsoever) into cannabis' dependence/harm liability or its role in their life problems.

The sample's predominantly youthful profile (two-thirds younger than 18 years, early-onset use, other drug use, low SES, low educational level, not enrolled/expelled from regular school, unemployed) accords with 'excess' risk of cannabis dependence globally [28, 49-52]. A growing group of young New Zealanders are raised in 'cannabis environments' where cannabis is 'normalized' and inter- generational use is common [53]. Most adolescents (86\%) reported familial drug problems usually involving cannabis, and having partners (66\%) and parents (30\%) who used cannabis regularly. More than a third reported cannabisrelated expulsions or suspensions - often multiple - from school. Using more potent cannabis products on at least 2 and up to 5 or more days $(89 \%)$ per week, and feeling 'stoned' at least 3 hours per day (65\%) exposed these New Zealand adolescents to risk of manifold harms, a vulnerability amplified by significantly increased alcohol and BZP use. Among society's most vulnerable [49-52], these at-risk youth epitomize the primary intended recipients of a screening and early intervention (SEI) approach.

A primary empirical question in this study was: do adolescents and adults exhibit different cannabis consumption, symptoms, and dependence severity profiles?

Table 4. Key Variables Associated with Diagnostic Transitions at Baseline and 12-Month Follow-Up (n=28)

\begin{tabular}{|c|c|c|c|c|c|c|c|c|c|c|}
\hline \multirow[t]{4}{*}{ Variable } & \multicolumn{8}{|c|}{ Diagnostic Transition Group } & \multirow{3}{*}{\multicolumn{2}{|c|}{$t$}} \\
\hline & \multicolumn{4}{|c|}{ Improved $(n=11)$} & \multicolumn{4}{|c|}{ Deteriorated $(n=17)$} & & \\
\hline & \multicolumn{2}{|c|}{ Baseline } & \multicolumn{2}{|c|}{ Follow Up } & \multicolumn{2}{|c|}{ Baseline } & \multicolumn{2}{|c|}{ Follow Up } & & \\
\hline & Mean & SD & Mean & SD & Mean & SD & Mean & SD & $\mathbf{B}$ & $\mathbf{F}-\mathbf{U}$ \\
\hline \multicolumn{11}{|l|}{ Cannabis Use $(n=28)$} \\
\hline Days used past 90 days & 23.09 & 25.93 & 14.36 & 14.21 & 34.94 & 25.59 & 50.88 & 25.99 & 1.19 & $4.25 * * *$ \\
\hline Days used past 30 days & 7.91 & 8.96 & 5.09 & 5.17 & 12.47 & 9.46 & 17.88 & 8.85 & 1.27 & $4.33 * * *$ \\
\hline \multicolumn{11}{|l|}{ Adolescents $(n=20)$} \\
\hline Days used past 90 days & 31.29 & 29.49 & 16.14 & 16.90 & 32.00 & 24.76 & 43.46 & 22.47 & .06 & $2.80 *$ \\
\hline Days used past 30 days & 11.00 & 10.05 & 5.86 & 6.09 & 10.54 & 7.87 & 15.07 & 7.68 & -.11 & $2.73 *$ \\
\hline \multicolumn{11}{|l|}{ Adults $(n=8)$} \\
\hline Days used past 90 days & 8.75 & 8.38 & 11.25 & 8.99 & 44.50 & 29.72 & 75.00 & 23.80 & 2.32 & $5.01 * *$ \\
\hline Days used past 30 days & 2.50 & 2.08 & 3.75 & 3.30 & 18.75 & 12.69 & 27.00 & 6.00 & $2.53 *$ & $6.78 * *$ \\
\hline Total symptoms $(n=28)$ & 4.09 & 1.87 & 2.73 & 1.42 & 2.76 & 1.56 & 6.65 & 2.47 & -2.03 & $4.75 * * *$ \\
\hline Adolescents $(n=20)$ & 3.86 & 1.46 & 2.71 & 1.25 & 2.38 & 1.39 & 6.38 & 2.60 & $-2.22 *$ & $3.49 * * *$ \\
\hline Adults $(n=8)$ & 4.50 & 2.65 & .75 & 1.89 & 4.00 & 1.63 & 7.50 & 2.08 & -.32 & $3.38 *$ \\
\hline SDS score $(n=28)$ & 2.45 & 1.81 & 2.82 & 1.17 & 2.18 & 1.19 & 4.06 & 1.35 & -.49 & $2.59 *$ \\
\hline Adolescents $(n=20)$ & 3.43 & 1.40 & 2.86 & 1.35 & 2.00 & 1.00 & 3.77 & 1.36 & $-2.66 *$ & 1.43 \\
\hline Adults $(n=8)$ & .75 & .96 & 2.75 & .96 & 2.75 & 1.71 & 5.0 & .82 & 2.04 & $3.58 * *$ \\
\hline
\end{tabular}

SD: Standard deviation. B: baseline. F-U: follow-up. $t$ : t-test value. ${ }^{*} \mathrm{p}<.05,{ }^{* *} \mathrm{p}<.01,{ }^{* * *} \mathrm{p}<.001$; all tests two-tailed. 
Consistent with global trends, adolescents had initiated and begun regular use earlier than their adult counterparts (Table 1). No adolescent/adult differences in number of symptoms (Table 2) or dependence severity (Table 3) were reported. Apart from adolescents more likely to report cannabisimpaired functioning at school/work or home (both assessments), and adults more likely to report withdrawal (baseline) and use in hazardous situations (follow-up), there were no significant adult/adolescent differences in likelihood of endorsing any DSM-IV/ICD-10 criteria. Juxtaposed with their physical and psychological developmental vulnerability, these indices indicate that despite substantially shorter using histories, adolescents in this sample were equally as disordered as their older, longer-using counterparts.

A second primary aim was to distinguish common transition groups according to participants' diagnoses at follow-up. Twelve-month data revealed only minor movement between diagnostic categories (Table 2). Reporting reduced symptoms does not necessarily indicate a less serious diagnosis. The sample's overall longitudinal diagnostic stability (166 unchanged) limited comparisons to two small transition groups (Table 4). The results that emerged were not unexpected: with few minor exceptions, while the 2 groups reported generally similar baseline levels of cannabis use, symptoms and severity, at follow-up the 17 adolescents/adults who had 'deteriorated' recorded significantly higher levels of cannabis use, symptoms, and dependence severity than the 11 adolescents/adults who had 'improved'.

The prevalence, constellation, and progression of CUD symptoms were another study question. As found in US research among users on a trajectory towards dependence [27-29], 'use in physically hazardous situations' was most prevalent overall, and loss of control over use ("persistent desire to control/cut down'/'used more/longer than intended') the most prevalent dependence criterion. Moreover, this criterion was the only (hence earliest) dependence feature endorsed by all 12 baseline diagnostic orphans. At 12-month follow-up, the 11 diagnostic orphans (who now included 3 baseline symptom-free participants) all reported 'loss of control over use' .symptoms.

Given the controversy about cannabis' physical dependence liability $[54,55]$, the striking 12-month increase in adolescents' tolerance ( $80 \%$ up from $54 \%$ at baseline) and withdrawal symptoms (48\% up from 28\%) merits comment. Tolerance and withdrawal have been frequently reported by dependent and non-dependent adolescents alike [31, 32]. Adolescents with marked tolerance to cannabis underwent clinically severe withdrawal symptoms over several weeks, their intensity unrelated to quantity or frequency of consumption, length of dependence, or age when regular use began [56]. Hartman et al. [57] concluded that adolescents endorsing 'withdrawal' criteria were likely to have the most severe cannabis problems. Indeed, both anecdotally and in response to measures in this study, many younger participants expressed despair at their own inability to quit or reduce their consumption. Whatever the susceptibility mechanism, younger adolescent users do appear especially vulnerable to neuroadaptation to cannabis and developing symptoms of physiological dependence [57, 58]. Hence, harnessing a burgeoning variety of innovative technologydelivered interventions [59], public health SEI initiatives should target vulnerable adolescents at risk/on a trajectory to cannabis dependence to arrest transition to more serious harms. Specifically developed and/or validated for adolescent and adult general and clinical populations, appropriate screening tools include the Cannabis Use Problems Identification Test [37] and the SDS [45].

Potential limitations of this naturalistic study of a relatively small convenience community sample of at-risk adolescent-adult users must be acknowledged. The selfreport, repeated-measures design raises possible reliability issues. All indicators, however, including toxicology reports and informal internal comparisons of participants' responses suggest over/under-reporting to be minimal, as found elsewhere $[60,61]$. The prospective data overcomes biases in most previous retrospective studies, and adolescents' restricted age range constrains a potential length (of use) bias and period (social trends, potency) effects. The face-to-face, standardized assessments (participants being their own longitudinal control) contrast to the relatively crude epidemiological surveys typically conducted. Given the interviewer's strict adherence to the CIDI-Auto guidelines, with cautious use of diagnostic concepts and terminology, and with no negative consequences for admitting cannabis/other drug use, adolescents' ready identification with dependence symptoms provide some assurance of the integrity of the process and the data generated. The sample's overall longitudinal diagnostic stability, and hence relatively small diagnostic transition groups to compare, limited the potential scope of analyses on available data. Finally, this study of a relatively small community convenience sample of at-risk cannabis users spanned a 24-month (12 months retrospective) window. More longitudinal studies that employ systematic sampling procedures to recruit a broader range of cannabis-using populations from both clinical and non-clinical community settings are required. Larger, more representative, more clinically-diverse and ethnically proportionate samples stratified by age, cannabis consumption levels, and spanning more elapsed time, are needed to obtain a clearer 'before' picture of adolescent cannabis users' transition from non-problematic, to regular, to symptom manifestation, to dependence. Fuller understanding of various pathways provides the foundation needed for effective targeted interventions.

\section{CONCLUSION}

While extending the international research on the natural history of CUD, this prospective New Zealand study confirms that younger adolescents can - and do - rapidly develop cannabis dependence, reporting similar and equally severe symptoms as longer-term adult users. The ostensibly inexorable course of problematic cannabis use makes a compelling case for stronger investment in public health SEI initiatives at an early age to avert or reduce harmful consequences of cannabis use in the community.

\section{CONFLICT OF INTEREST}

The authors confirm that this article content has no conflict of interest. 


\section{ACKNOWLEDGEMENTS}

Declared none.

\section{REFERENCES}

[1] United Nations Office of Drugs and Crime. World Drug Report 2011. Oxford: Oxford University Press, 2011. Available online: www.unodc.org [Accessed June, 2012].

[2] Hall W. The adverse health effects of cannabis use: What are they, and what are their implications for policy? Int J Drug Policy 2009; 20: 458-466.

[3] Anthony JC. The epidemiology of cannabis dependence. In: Roffman RA, Stephens RS, Eds. Cannabis dependence: Its nature, consequences and treatment. International Research Monographs in the Addictions. Cambridgeshire: University Press, 2006: pp. 58105.

[4] Room R, Fischer B, Hall W, et al. Cannabis policy: moving beyond stalemate. Oxford: Oxford University Press, 2010.

[5] Schneider M. Puberty as a highly vulnerable developmental period for the consequences of cannabis exposure. Addict Biol 2008; 13: 253-63.

[6] Chen K, Kandel DB, Davies M. Relationship between frequency and quantity of marijuana use and last year proxy dependence among adolescents and adults in the United States. Drug Alcohol Depend 1997; 46: 53-67.

[7] Rey JM, Martin A, Krabman P. Is the party over? Cannabis and juvenile psychiatric disorder: The past 10 years. J Acad Child Adolesc Psychiatry 2004; 43:1194-1205.

[8] Behrendt S, Wittchen H-U, Hofler M, et al. Transition from first substance use to substance use disorders in adolescence: is early onset associated with a rapid escalation? Drug Alcohol Depend 2008; 99: 68-78

[9] Kokkevi A, Gabhainn SN, Spyropoulou M, et al. Early Initiation of Cannabis Use: A Cross-national European Perspective. J Adolesc Health 2006; 39: 712-9.

[10] Ellickson PL, Martino CC, Collins RL. Marijuana use from adolescence to young adulthood: multiple developmental trajectories and their associated outcomes. Health Psychol 2004; 23: 299-307.

[11] Chen C-Y, Storr CL, Anthony JC. Early-onset drug use and risk for drug dependence problems. Addict Behav 2009; 34: 319-322.

[12] Degenhardt L, Coffey C, Carlin JB, et al. Outcomes of occasional cannabis use in adolescence: 10-year follow-up study in Victoria, Australia. Br J Psychiatry 2010; 196: 290-5.

[13] Meier MH, Caspi A, Antony A, et al. Persistent cannabis users show neuropsychological decline from childhood to midlife. Proc Natl Acad Sci USA 2012; 109: E2657.

[14] Patton GC, Coffey C, Lynskey, MY, et al. Trajectories of adolescent alcohol and cannabis use into young adulthood. Addiction 2007; 102: 607-615.

[15] Copeland J, Swift W. Cannabis use disorder: Epidemiology and management. Int. Rev Psychiatry 2009; 21: 96-103.

[16] Kandel DB, Chen K. Types of marijuana users by longitudinal course. J Studies Alcohol 2000; 61:367-378.

[17] Coffey C, Lynskey M, Wolfe R, et al. Initiation and progression of cannabis use in a population-based Australian adolescent longitudinal sample. Addiction 2000; 95: 1679-1690.

[18] Compton WM, Grant BF, Colliver JD, et al. Prevalence of Marijuana Use Disorders in the United States 1991-1992 and 20012002. JAMA 2004; 291: 2114-2121.

[19] Poulton R, Moffitt TE, Harrington H, et al. Persistence and perceived consequences of cannabis use and dependence among young adults: implications for policy. N Z Med J 2001; 114: 544-7.

[20] Degenhardt L, Coffey C, Carlin, JB, et al. Are diagnostic orphans at risk of developing cannabis abuse or dependence? Four-year follow-up of young adult cannabis users not meeting diagnostic criteria. Drug Alcohol Depend 2008; 92: 86-90.

[21] Schulenberg JE, Merline AC, Johnston LD et al. Trajectories of marijuana use during the transition to adulthood: the big picture based on national panel data. J Drug Issues 2005; 35: 255-279.

[22] Windle M, Wiesner M. Trajectories of marijuana use from adolescence to young adulthood: Predictors and outcomes. Dev Psychopathol 2004; 16:1007-1027.

[23] Brook JS, Zhang c, Brook DW. Antisocial behavior at age 37: developmental trajectories of marijuana use extending from adolescence to adulthood. Am J Addict 2011; 20: 509-15.
[24] Agrawal A, Budney AJ, Lynskey MT. The co-occurring use and misuse of cannabis and tobacco: a review. Addiction 2012; 107: 1221-1233.

[25] Flory K, Lynam D, Milich R. et al. Early adolescent through young adult alcohol and marijuana use trajectories: early predictors, young adult outcomes, and predictive utility. Dev Psychopathol 2004; 16: 193-213.

[26] Tucker JS, Ellickson PL, Orlando M, et al. Substance use trajectories from early adolescence to emerging adulthood: a comparison of smoking, binge drinking, and marijuana use. J Drug Issues 2005; 22: 307-322.

[27] Chen C-Y, Anthony J. Possible age-associated bias in reporting of clinical features of drug dependence: epidemiological evidence on adolescent onset marijuana use. Addiction 2003; 98:71-82.

[28] Chen C-Y, O’Brien MS, Anthony JC. Who becomes cannabis dependent soon after onset of use? Epidemiological evidence from the United States: 2000-2001. Drug Alcohol Depend 2005; 79: 1122.

[29] Rosenberg MF, Anthony JC. Early clinical manifestations of cannabis dependence in a community sample. Drug Alcohol Depend 2001; 64: 123-131.

[30] Coffey C, Carlin JB, Degenhardt L, et al. Cannabis dependence in young adults: an Australian population study. Addiction 2002; 97:187-194.

[31] Young SE, Corley RP, Stallings MC, et al. Substance use, abuse and dependence in adolescence: prevalence, symptom profiles and correlates. Drug Alcohol Depend 2002; 68: 309-322.

[32] Nocon A, Wittchen H-U, Pfister H, et al. Dependence symptoms in young cannabis users? A prospective epidemiological study. J Psychiatric Res 2005; 40: 394-403.

[33] Degenhardt L, Chiu W-T, Sampson N, et al. Toward a Global View of Alcohol, Tobacco, Cannabis, and Cocaine Use: Findings from the WHO World Mental Health Surveys. PLoS Med 2008; 5: e141: 1053-1067.

[34] Ministry of Health. Drug use in New Zealand: key results of the 2007/2008 New Zealand Alcohol and Drug Use Survey. Wellington, New Zealand: MOH 2010.

[35] Mason K, Hewitt A, Stefanogiannis N. Drug use in New Zealand: key results of the 2007/2008 New Zealand Alcohol and Drug Use Survey. Wellington, New Zealand: Ministry of Health, 2010.

[36] Monshouwer K, Smit F, de Graaf R, et al. First cannabis use: does onset shift to younger ages? Findings from 1988 to 2003 from the Dutch National School Survey on Substance Use. Addiction 2005; 100: 963-970.

[37] Bashford J, Flett R, Copeland J. The Cannabis Use Problems Identification Test (CUPIT): development, reliability, concurrent and predictive validity among adolescents and adults. Addiction 2010; 105: 615-25

[38] Sobell LC, Sobell MB. Timeline Follow-Back: A technique for assessing self-reported alcohol consumption. In: Litten R, Allen J, Eds. Measuring alcohol consumption; Psychosocial and biochemical methods. Totowa, NJ: Humana Press Inc, 1992: pp. 41-69.

[39] Fals-Stewart W, O'Farrell TJ, Freitas TT, et al. The timeline followback reports of psychoactive substance use by drug-abusing patients: psychometric properties. J Consult Clin Psychol 2000; 68: 134-44.

[40] Schwartz JG, Zollars PR, Okorodudu AO, et al. Accuracy of common drug screen tests. Am J Emerg Med 1991; 9: 166-170.

[41] Sobell LC, Kwan E, Sobell MB. Reliability of a Drug History Questionnaire (DHQ). Addict Behav 1995; 20: 233-241.

[42] American Psychiatric Association. Diagnostic and statistical manual of mental disorders, $4^{\text {th }}$ edn. (DSM-IV). Washington, DC: American Psychiatric Association, 1994.

[43] World Health Organization. International Classification of Diseases-Tenth Revision (ICD-10). Geneva, Switzerland: World Health Organization, 1992.

[44] World Health Organization. Composite International Diagnostic Interview, version 2.1. Geneva, Switzerland: World Health Organization, 1997.

[45] Martin G, Copeland J, Gates P, et al. The Severity of Dependence Scale (SDS) in an adolescent population of cannabis users: reliability, validity and diagnostic cut-off. Drug Alcohol Depend 2006; 83: 90-3. 
[46] Biernacki P, Waldorf D. Snowball sampling: problems and techniques of chain-referral sampling. Soc Methods Res 1981; 10: 141-63.

[47] SPSS Inc. SPSS Base 12.0. User's Guide. Chicago, IL: SPSS Inc., 2003.

[48] Degenhardt L, Lynskey M, Coffey C, et al. 'Diagnostic orphans' among young adult cannabis users: persons who report dependence symptoms but do not meet diagnostic criteria. Drug Alcohol Depend 2002; 67: 205-12.

[49] Coffey C, Carlin JB, Lynskey M. Adolescent precursors of cannabis dependence: findings from the Victorian Adolescent Health Cohort Study. Br J Psychiatry 2003; 182: 330-6.

[50] van den Bree MB, Pickworth WB. Risk factors predicting changes in marijuana involvement in teenagers. Arch Gen Psychiatry 2005; 62: 311-19.

[51] Winters KC, Lee CY. Likelihood of developing an alcohol and cannabis use disorder during youth: Association with recent use and age. Drug Alcohol Depend 2008; 92:239-247.

[52] von Sydow K, Leib R, Pfister H. et al. What predicts incident use of cannabis and progression to abuse and dependence? A 4-year prospective examination of risk factors in a community sample of adolescents and young adults. Drug Alcohol Depend 2002; 49-64.

[53] Durie M. Mauri Ora: The dynamics of Māori health. Auckland, NZ: Oxford University Press, 2001.
[54] Budney AJ, Hughes JR. The cannabis withdrawal syndrome. Curr Opin Psychiatry 2006; 19: 233-8.

[55] Budney AJ, Stanger C. Cannabis use and misuse. In Rey JM (ed), IACAPRP e-textbook of child and adolescent mental health. Geneva: International Association for Child and Adolescent Psychiatry and Allied Professions 2012; pp. 1-28.

[56] Milin R, Manion I, Dare G, et al. Prospective assessment of cannabis withdrawal in adolescents with cannabis dependence. $\mathrm{J}$ Am Acad Child Adolesc Psychiatry 2008; 47: 174-9.

[57] Hartman CA, Gelhorn H, Crowley TJ, et al. Item response theory analysis of DSM-IV cannabis abuse and dependence criteria in adolescents. J Am Acad Child Adolesc Psychiatry 2008; 47:165173.

[58] Solowij N, Grenyer BF. Are the adverse consequences of cannabis use age-dependent? Addiction 2002; 97:1083-6.

[59] Copeland J. Application of technology in the prevention and treatment of substance use disorders and related problems: opportunities and challenges. Subst Use Misuse 2011; 46:112-3.

[60] Gignac M, Wilens TE, Biederman J, et al. Assessing cannabis use in adolescents and young adults: what do urine screens and parental report tell you? J Child Adolesc Pharmacol 2005; 15: 742-50.

[61] Mennes CE, Abdallah AB, Cottler LB. The reliability of selfreported cannabis abuse, dependence and withdrawal symptoms: multisite study of differences between general population and treatment groups. Addict Behav 2009; 34: 223-6.

Received: May 2, 2013

Revised: October 30, 2013

Accepted: November 7, 2013

(C) Bashford et al.; Licensee Bentham Open.

This is an open access article licensed under the terms of the Creative Commons Attribution Non-Commercial License (http://creativecommons.org/licenses/ by-nc/3.0/) which permits unrestricted, non-commercial use, distribution and reproduction in any medium, provided the work is properly cited. 